\title{
TYPE-2 DIABETES MELLITUS AND BRAIN STEM EVOKED RESPONSE AUDIOMETRY: A CASE CONTROL STUDY
}

Praveen S. Yousuf1, Chhaya Batham ${ }^{2}$

1 Professor and HOD, Department of Physiology, LNMC \& RC, Bhopal.

$2^{2}$ nd Year Post Graduate Student, Department of Physiology, LNMC \& RC, Bhopal.

\section{ABSTRACT}

\section{BACKGROUND AND OBJECTIVE}

Type-2 Diabetes Mellitus (T2DM) causes pathophysiological changes in multiple organ system. The peripheral, autonomic and central neuropathy is known to occur in T2DM, which can be studied electrophysiologically.

\section{AIM}

Present study is aimed to evaluate functional integrity of auditory pathway in T2DM by Brainstem Evoked Response Audiometry (BERA).

\section{MATERIAL AND METHOD}

In the present case control study, BERA was recorded from the scalp of 20 T2DM patients aged 30-65 years and were compared with age matched 20 healthy controls. The BERA was performed using EMG Octopus, Clarity Medical Pvt. Ltd. The latencies of wave I, III, V and Wave I-III, I-V and III-V interpeak latencies of both right and left ear were recorded at 70dBHL.

\section{STATISTICAL RESULT AND USE}

Mean \pm SD of latencies of wave I, III, V and interpeak latency of I-III, I-V and III-V were estimated of T2DM and healthy controls. The significant differences between the two groups were assessed using unpaired student ' $t$ ' test for T2DM and control groups using GraphPad QuickCalcs calculator. P value $<0.05$ was considered to be significant.

\section{RESULT}

In T2DM BERA study revealed statistically significant $(\mathrm{p}<0.05)$ prolonged latencies of wave I, III and V in both right $(1.81 \pm 0.33 \mathrm{~ms}, 3.96 \pm 0.32 \mathrm{~ms}, 5.60 \pm 0.25 \mathrm{~ms})$ and left $(1.96 \pm 0.24 \mathrm{~ms}, 3.79 \pm 0.22 \mathrm{~ms}, 5.67 \pm 0.25 \mathrm{~ms})$ ear as compared to controls at $70 \mathrm{~dB}$. Wave III-V interpeak latency of left ear $(1.87 \pm 0.31,1.85 \pm 0.41 \mathrm{~ms})$ and wave I-III $(2.51 \pm 0.42 \mathrm{~ms}, 1.96 \pm 0.48 \mathrm{~ms})$ and III-V $(2.01 \pm 0.43 \mathrm{~ms}, 1.76 \pm 0.45 \mathrm{~ms})$ of right ear was prolonged in diabetic patient as compared to controls, although no significant difference was obtained $(\mathrm{p}<0.05)$.

\section{INTERPRETATION AND CONCLUSION}

Increase in absolute latencies and interpeak latencies inT2DM patients suggest involvement of central neuronal axis at the level of brain stem and midbrain.

\section{KEYWORDS}

Type 2 Diabetes Mellitus, Central Neuropathy, Brainstem Evoked Response Audiometry.

HOW TO CITE THIS ARTICLE: Yousuf PS, Batham C. Type-2 diabetes mellitus and brain stem evoked response audiometry: a case control study. J. Evolution Med. Dent. Sci. 2016;5(8):359-362, DOI: 10.14260/jemds/2016/81

\section{INTRODUCTION}

Diabetes mellitus is an endocrinological and metabolic disorder that involves the dysregulation of use and/or the production of insulin, the hormone that is required for regulation of glucose in the body. Hyperglycaemia or elevated blood glucose levels is the hallmark characteristic of the disease. ${ }^{1}$ T2DM is characterized by a resistance to the action of insulin, a relative deficiency of insulin production or both. Insulin resistance leads to deficiency in the necessary insulin action required for the proper metabolism of carbohydrates, fats and proteins. ${ }^{1}$ It is associated with high morbidity and mortality due to its macrovascular and microvascular complications like myocardial infarction, hypertension, peripheral vascular disease, neuropathy, nephropathy and retinopathy. ${ }^{2}$

Financial or Other, Competing Interest: None.

Submission 15-12-2015, Peer Review 09-01-2016,

Acceptance 18-01-2016, Published 28-01-2016.

Corresponding Author:

Dr. Chhaya Batham,

Department of Physiology,

LNMC \& RC, Bhopal.

E-mail: chhayabatham@gmail.com

DOI: $10.14260 /$ jemds/2016/81
Diabetic neuropathy can be classified as peripheral, autonomic, proximal or focal affecting different parts of the body in various ways. Autonomic and peripheral neuropathy, nephropathy, retinopathy and hearing impairment are some of the late complications of T2DM. ${ }^{2}$ Micro- and macroangiopathic disturbances and myelin degeneration are responsible for late onset of neuropathy. Diabetes related hearing impairment has been described as sensory neural in origin, implying that the lesion may be cochlear or of the eight cranial nerve, but evidence favouring a specific mechanism is insufficient. ${ }^{3}$ High frequency progressive sensorineural hearing loss is reported to occur in the majority of the patients with diabetes mellitus because of cochlear and eighth nerve involvement. ${ }^{4}$

It is suggested that Brain Stem Auditory evoked potential (BERA) can demonstrate electrophysiologically any lesion from acoustic nerve to Brain stem and can be used in diabetics to show subclinical variances and central neuropathy. 5 At present BERA has become a routine part of the standard audiological test battery. It is based upon the study of electrical potential generated by auditory pathway in response to sound stimuli. 
Their latencies are quite specific and their reproducibility is very good. The differences in latencies between these peaks are measure of the conduction time between the brainstem generators. Interpeak latencies I-III, III-V and I-V are indicative of central conduction from brainstem to mid-brain level in auditory pathway. ${ }^{6}$

With this background present study was undertaken to evaluate auditory function and detection of central neuropathy in patient with T2DM.

\section{MATERIALS AND METHODS}

The present study was conducted in the Department of Physiology, LNMC Bhopal with the approval of institutional ethical committee.

(Letter No. LNMC/Dean/2015/2146 dated12/02/2015).

Patients were referred to Department of ENT for complete check-up to exclude any ear pathology. Patients with acute complications of diabetes like diabetic ketoacidosis, non-ketotic hyperosmolar coma, history of ear discharge, associated endocrinal disorder, history of drug intake known to cause central and peripheral neuropathy or ototoxic drug were excluded from the study.

Based on inclusion and exclusion criteria and willingness of subjects to participate in the study 20 T2DM patients (Age 30-65 years, Male-12, Female-08) and 20 healthy controls (Age 30-65 years) were selected for the study. Proper history and anthropometric measurements of all the subjects included in the study were done. Complete clinical examination including general systemic and audiometric examination were done. Biochemically random blood glucose was estimated to confirm T2DM by GOD POD method. ${ }^{7}$

Bera was recorded using EMG Octopus by Clarity Medical Pvt. Ltd. with 2 amplifiers hardware version 2.5 and software version 4.2 in sound proof room with patient in relaxed supine position. Prior to the test the procedure was explained to the patient. Skin of the forehead and of mastoid process were cleaned with acetone soaked swab. Then electrodes were properly cleaned and placed using 10-20 conductive paste applied in the recess of electrode and was then adhered to cleaned surface of their respective side. Standard silver chloride electrodes of $1 \mathrm{~cm}$ diameter was placed according to 10-20 International System. ${ }^{8}$

Ground Electrode: Fz

Reference Electrode (Cz): Vertex

Active Electrode (Oz): Mastoid Process

The stimulus was given using head phone. The stimulus rate was set at 11 clicks/sec., sweep speed was set at $1 \mathrm{~ms} /$ div., low filter was set at $100 \mathrm{~Hz}$ and high filter at $3 \mathrm{KHz}$. Recording were taken at $70 \mathrm{dBHL}$ for $3 \mathrm{KHz}$ frequency with rare click stimulus. Averaging was done for 2000 epochs. Impedance was kept less than $5 \mathrm{k} \Omega$. At least 2 recordings were taken to confirm the re-producibility of wave form and the absolute latencies of wave I, III and V and interpeak latencies I-III, III-V, and I-V were recorded.

Results of T2DM patients were compared with those of the healthy subjects. Mean \pm SD of absolute latencies of wave I, III, $\mathrm{V}$ and interpeak latencies I-III, III-V and I-V were calculated. The significant difference between the two groups were assessed using unpaired student ' $\mathrm{t}$ ' test. $\mathrm{P}$ value $<0.05$ was considered statistically significant.

\section{OBSERVATION AND RESULT}

\begin{tabular}{|c|c|c|c|c|c|}
\hline $\begin{array}{c}\text { Sl. } \\
\text { No. }\end{array}$ & Parameters & $\begin{array}{c}\text { Control } \\
\text { Group }\end{array}$ & $\begin{array}{c}\text { Diabetic } \\
\text { Group }\end{array}$ & $\begin{array}{c}\text { t- } \\
\text { value }\end{array}$ & $\begin{array}{c}\text { p- } \\
\text { value }\end{array}$ \\
\hline 1 & Age (Years) & $47.25 \pm 6.41$ & $51.75 \pm 11.15$ & 1.56 & NS \\
\hline 2 & $\begin{array}{c}{ }^{*} \mathrm{RBG} \\
(\mathrm{mg} / \mathrm{dl})\end{array}$ & $101.35 \pm 27.07$ & $178.31 \pm 76.58$ & 4.23 & $<0.00$ \\
\hline 3 & $\begin{array}{c}\mathrm{Height} \\
(\mathrm{cm})\end{array}$ & $157.10 \pm 10.36$ & $154.42 \pm 1.90$ & 0.91 & $\mathrm{NS}$ \\
\hline 4 & $\begin{array}{c}\text { Weight } \\
(\mathrm{Kg})\end{array}$ & $62.73 \pm 10.20$ & $62.26 \pm 13.27$ & 0.12 & $\mathrm{NS}$ \\
\hline 5 & $\begin{array}{c}\mathrm{BMI} \\
\left(\mathrm{Kg} / \mathrm{m}^{2}\right)\end{array}$ & $25.47 \pm 4.10$ & $26.08 \pm 5.04$ & 0.42 & $\mathrm{NS}$ \\
\hline \multicolumn{6}{|c|}{$\begin{array}{c}\text { Table 1: Comparison of anthropometric } \\
\text { measurements between control and diabetic group }\end{array}$} \\
\hline
\end{tabular}

*Random blood glucose was found to be higher in diabetic patients as compared to control group.

\begin{tabular}{|c|c|c|c|c|}
\hline $\begin{array}{c}\text { Wave } \\
\text { Latency } \\
\text { (ms) }\end{array}$ & $\begin{array}{l}\text { Control } \\
\text { Group } \\
(\mathrm{n}=20)\end{array}$ & $\begin{array}{c}\text { Diabetic } \\
\text { Group } \\
(n=20)\end{array}$ & $\begin{array}{c}\text { t- } \\
\text { value }\end{array}$ & $\begin{array}{c}\text { p- } \\
\text { value }\end{array}$ \\
\hline I & $1.62 \pm 0.29$ & $1.96 \pm 0.24$ & 4.03 & $<0.0001^{*}$ \\
\hline III & $3.63 \pm 0.25$ & $3.79 \pm 0.22$ & 2.14 & $<0.05^{*}$ \\
\hline $\mathrm{V}$ & $5.41 \pm 0.37$ & $5.67 \pm 0.25$ & 2.60 & $<0.01^{*}$ \\
\hline I-III & $2.02 \pm 0.41$ & $1.60 \pm 0.61$ & - & - \\
\hline $\mathrm{I}-\mathrm{V}$ & $3.89 \pm 0.36$ & $3.71 \pm 0.39$ & - & - \\
\hline III-V & $1.85 \pm 0.41$ & $1.87 \pm 0.31$ & 0.71 & NS \\
\hline
\end{tabular}

${ }^{*} \mathrm{P}<0.05$ statistically significant, NS- not significant

Statistically significant delay in absolute latencies of wave I, III, V of left ear in diabetic group as compared to control group was recorded. Although wave III-V interpeak latency was found to be higher in diabetic patients as compared to controls, but difference was not statistically significant.

\begin{tabular}{|c|c|c|c|c|}
\hline $\begin{array}{c}\text { Wave } \\
\text { Latency } \\
(\mathbf{m s})\end{array}$ & $\begin{array}{c}\text { Control } \\
\text { Group } \\
(\mathbf{n}=\mathbf{2 0})\end{array}$ & $\begin{array}{c}\text { Diabetic } \\
\text { Group } \\
(\mathbf{n}=\mathbf{2 0})\end{array}$ & t-value & $\begin{array}{c}\mathbf{p}- \\
\text { value }\end{array}$ \\
\hline $\mathrm{I}$ & $1.60 \pm 0.29$ & $1.81 \pm 0.33$ & 2.13 & $<0.05$ \\
\hline $\mathrm{III}$ & $3.56 \pm 0.34$ & $3.96 \pm 0.32$ & 3.83 & $<0.001$ \\
\hline $\mathrm{V}$ & $5.33 \pm 0.51$ & $5.60 \pm 0.25$ & 2.12 & $<0.05$ \\
\hline $\mathrm{I}-\mathrm{III}$ & $1.96 \pm 0.48$ & $2.51 \pm 0.42$ & 1.33 & $\mathrm{NS}$ \\
\hline $\mathrm{I}-\mathrm{V}$ & $3.45 \pm 0.32$ & $3.72 \pm 0.48$ & - & - \\
\hline $\mathrm{III}-\mathrm{V}$ & $1.76 \pm 0.45$ & $2.01 \pm 0.43$ & 1.79 & $\mathrm{NS}$ \\
\hline Table 3: Comparison of absolute latencies and interpeak \\
latencies of right ear in normal subjects and in patients with \\
diabetes mellitus at 70dB
\end{tabular}

Absolute latencies of wave I, III and V was significantly prolonged in diabetic as compared to controls. Wave I-III and III-V interpeak latency was found prolonged in diabetic as compared to control, but difference was not statistically significant.

\section{DISCUSSION}

BERA represents the electrical events generated along the auditory pathway recorded from the scalp by far field averaging methods. ${ }^{9,10}$ The response to a click consist of 6 or 7 small vertex positive waves recorded in the first $10 \mathrm{~ms}$ after the stimulus. Wave I is produced by the acoustic nerve activity that wave II can reflect the activity of the cochlear nucleus with a contribution from the auditory nerve, that Wave III can be referred to the generators in the superior olivary complex and the lateral leminiscii, that the wave IV-V complex is generated in the axons and/or nuclei of the lateral leminiscii and probably also from inferior colliculi. ${ }^{11}$ 
Peripheral neuropathy along with involvement of central neuronal axis associated with diabetes is responsible for myriad of symptoms. ${ }^{12}$ Degenerative abnormalities of the brain tissue and atrophy of the spiral ganglion of the cochlea in the patients of diabetes mellitus suggests the presence of central neuropathy. 13 T2DM subjects are more prone to develop sensory neural hearing loss. ${ }^{14}$ Friedman et al. ${ }^{15}$ and Goldsher et al. ${ }^{16}$ reported sensory neural deafness in 55\% and 94\% T2DM patients with neuropathy. In the present study abnormal BERA was recorded in 80\% T2DM patients in left ear and $98 \%$ cases in right ear. Asymmetrical recording may be due to less duration of the disease in maximum number of cases. Studies in the literature have disagreed about the duration of disease and control of diabetic status to complications. ${ }^{17,18}$ Contrary to the findings of Olsson et al.19 and Reske et al.20 who concluded brain involvement in longstanding diabetes.

Study by Triana et al. ${ }^{21}$ also found loss of sensory hair cells in cochlea in diabetics resulting in cochlear hearing loss.

Gupta R, et al. (2014).22 in their study on 25 T2DM patients found prolonged wave III and V, interpeak I-III, III-V, III-V at $70 \mathrm{~dB}$. They reported abnormal findings in 18 cases.

Similar to our study prolonged wave I and wave III latency was seen in T2DM as compared to control. Wave $\mathrm{V}$ latency was normal in maximum number of cases in both right and left ear.

Wave I-III interpeak latency was delayed in right ear in $55 \%$ cases in T2DM suggesting delayed transmission of auditory pathway of diabetes at level of brainstem and midbrain. Similar prolongation of wave I-III and I-V interpeak latency was reported at $70 \mathrm{~dB}$ by Siddique et al. (2014). ${ }^{7}$ and Fiddle et al. (1984). ${ }^{23}$

In our study, 04 patients with duration $>10$ year presented with prolonged wave I latency in $75 \%$ patients. Although neither significant prolongation nor any correlation could be established with duration of disease similar to Verma A. ${ }^{13}$ et al. Sharma Ravindera. ${ }^{24}$ and Sidiqqui et al. (2014). ${ }^{7}$ reported delayed BERA in $92.3 \%$ and $91 \%$ patients with duration $>10$ years respectively.

Abnormal brainstem evoked responses were more in patient with duration $>10$ years is reported by many authors.13,24 Microangiopathy, a long-term complication explain the cause of abnormal BERA in long duration T2DM (10 years) as reported by Jorgenson et al. (1962).25

Some studies. ${ }^{21}$ found that the hearing loss is irreversible even after the control of diabetes, so we recommend appropriate preventions to be taken in T2DM patients before the development of complication.

\section{CONCLUSION}

BERA is simple non-invasive procedure to detect early impairment of acoustic nerve and CNS pathway central neuropathy in diabetes mellitus. CNS involvement does not seem to be related with duration of diabetes or presence of chronic complications. BERA recording can represent an objective clinically useful non-invasive procedure to stress the early impairment both of the auditory nerve and of brainstem function is not related to blood glucose level. However, duration of illness and presence of peripheral neuropathy are definite risk factor for the development of central neuropathy.

\section{REFERENCES}

1. Report of Expert Committee on the Diagnosis and classification of Diabetes mellitus, Diabetes care, 2008;31(supp11):S55-S60.

2. Giancintamiscio, Giulia G, Amelia B, et al. Obesity and peripheral neuropathy risk: a dangerous lesion. Journal of peripheral nervous system, 2005;10:354-58.

3. Bainbridge KE, Cheng YJ, Cowie CC. Potential mediators of diabetes related hearing impairment in the US population. Diabetes care April 2010;33(4):811-16.

4. Durmus C, Yestiser S, Durmuso. Auditory brain stem responses in insulin dependent and non-insulin dependent diabetic subjects with normal hearing. Intr J Audiol 2004;43:29-33.

5. Seidi R, Birnbacher R, Bernert G, et al. Brainstem auditory evoked potentials and visually evoked potentials in young patients with IDDM.

Diabetic care, Nov 1996;(11):1220-23.

6. Siddiqui S, Gupta R, Aslam M, et al. Type-2 diabetes mellitus and auditory brainstem response. IJEM, October 20, 2014; IP (5):122,168,150.

7. Trinder P. Determination of blood glucose using an oxidase peroxidase system with anon carcinogenic chromogen. J Clin Pathol 1969;22:158-61.

8. Misra UK and Kalita J. Clinical Neurophysiology Third Edition Elsevier 2014. Chapter-9 Brainstem Auditory Evoked Potential page 303.

9. Jewett DL, Romano MN and Williston JS. Human auditory evoked potentials: possible brainstem components detected on the scalp. Science 1970;167:1517-18.

10. Starr A, Achor LJ. Auditory brainstem responses in neurological disease. Arch Neurol 1975;32:761-68.

11. Buchwald JS, Moore EJ. Bases of auditory brain-stem evoked responses, New York, Grune and Stratton, 1983; Pg. 157-195.

12. Verma A, Bist M, Ahuja GK, et al. Involvement of central nervous system in diabetes mellitus. Journal of Neurology, Neurosurgery and Psychiatry. 1984;47:414-16.

13. Makishima K, Tanaka K. Pathological changes of inner ear and central pathway in diabetics. Ann Otolaryngol 1971;80:218-28.

14. Friedman SA, Schulman RH, Weiss S. Hearing and diabetic neuropathy. Arch Intern Med 1975;135:573-76.

15. Goldsher M, Pratt H, Hassan A, et al. Auditory brainstem evoked potentials in insulin-dependent diabetics with and without peripheral neuropathy. Acta Otolaryngol 1986;102:204-8.

16. Davlosa RA, Caulfield JG, Rees SB, et al. Preliminary observations on subjects with prediabetes. Diabetes 1963;12:508-18.

17. Gunn GC, Dobson HL, Gray J, et al. Studies of pulse wave velocity in potential diabetic subjects. Diabetes 1965;14:489-92.

18. Olsson Y, Soderberg Y, Sourander $\mathrm{P}$, et al. A pathoanatomical study of the central and peripheral nervous system in diabetes of early onset and long duration. Pathol Eur 1968;3:62-79.

19. Reske-Nielsen E, Lund Back K. Pathological changes in the central and peripheral nervous system of young longterm diabetics. Diabetologia 1968;4:34-43. 
20. Sharma DR, Gupta AK, Saxena RK, et al. Audiovestibular changes in diabetes mellitus. IJO \& HNS, April-June, 1999; Vol. 51, No. 2:40-44.

21. Gupta R, Mohd. A, Hasan SA, et al. Type-2 diabetes mellitus and auditory brainstem responses-a hospital based study. www.ijem.com September 2014, ip: 122.168.46.240:9-11.

22. Fidele D, Martin A, Cardone C, et al. Impaired auditory brain stem evoked response in diabetes mellitus. Diabetes 1984; 33:1805-1809.
23. Sharma R, Gupta SC, Tyagi I, et al. Indian Journal of Otolaryngology and Head and Neck Surgery JulySeptember 2000; Vol. 52(3)

24. Jorgenson MB, Buch NH. Studies on inner ear function and cranial nerves in diabetics. Acta-Otolaryngol: 1962(53); 350-364.

25. Sharma DR, Gupta AK, Saxena RK, et al. Audiovestibular changes in diabetes mellitus. IJO \& HNS; April-June, 1999; 51(2):40-44. 